\title{
Rapid amplified enzyme linked immunosorbent assay evaluated for detecting herpes simplex virus
}

\author{
J A EMSBROEK, P OVERDIEK, R A COUTINHO \\ From the Department of Infectious Diseases, Municipal Health Service, Amsterdam, The Netherlands
}

SUMMARY A new amplified enzyme linked immunosorbent assay (amplified ELISA) kit for detecting herpes simplex virus (HSV) antigen was evaluated. Duplicate swabs were taken from 180 patients with clinically suspected herpes lesions. Tests were performed on a direct swab extract and viral transport medium containing a swab.

Of the 93 culture positive specimens, 78 of the extracted samples (sensitivity $83.9 \%$ ) and 72 of the swabs in transport medium (sensitivity $77.4 \%$ ) were positive by amplified ELISA. A higher sensitivity $(49 / 54,90 \cdot 7 \%)$ was obtained when the extracted swab was taken first. In early lesions the sensitivity was $93.8 \%$ but in late lesions it was $73.3 \%$. This ELISA therefore offers an alternative to culture for early lesions, but culture is the method of choice for differential diagnosis of genital ulceration. As the specificity was $94.3 \%$, this test is acceptable for testing populations with a high prevalence of HSV infection, but culture should be used for screening populations in which the disease is rare.

Until recently the enzyme linked immunosorbent assay (ELISA) for the direct detection of herpes simplex virus (HSV) in clinical specimens was not very sensitive compared with conventional virus culture..$^{1-5}$ The ELISA, however, has advantages over virus culture regarding speed and ease of handling of specimens. This has become more important as an effective antiviral treatment, which has to be started as early as possible, is now available. An enzyme amplification system that increases the sensitivity of antigen detection has been incorporated into an ELISA for HSV. Clayton $e t$ al found that this recently developed enzyme amplified ELISA had greater absolute sensitivity than a conventional ELISA. ${ }^{6}$

The purpose of this trial was to assess the sensitivity, specificity, reproducibility, and ease of use of this new enzyme amplified ELISA in a routine virological laboratory.

\section{Patients and methods}

We collected specimens from 180 patients attending sexually transmitted disease (STD) clinics in Amsterdam who had clinical indications of active HSV infections. Clinical data noted about the patients included sex, age, and site and type of lesion. Two

\footnotetext{
Address for reprints: R A Coutinho, Municipal Health Service, Department of Infectious Diseases, P O Box 20244, 1000 HE Amsterdam, The Netherlands
}

Accepted for publication 23 July 1987 specimens were taken from each patient, one with a dacron tipped plastic swab provided by the manufacturer and the other with a sterile wooden swab with cotton tip used routinely for virus culture by our laboratory. The culture swab was taken first in the first 82 patients, and the sequence was reversed in the last 98 patients. Of the first 82 patients, 31 had early lesions (vesicles) and 51 late lesions (ulcers). Of the last 98 patients 48 had vesicles and 50 ulcers. The ELISA swab was treated with $1 \mathrm{ml}$ extraction fluid before testing by the amplified ELISA. The culture swab was put into $2 \mathrm{ml}$ Hanks' transport medium (Hanks's TC (tissue culture), Difco $5774-72-6$ ) $150 \mathrm{ml}$, sodium bicarbonate (Merck 6329) $0.5 \mathrm{~g}$, penicillin $150000 \mathrm{IU}$, streptomycin $150 \mathrm{mg}$, and distilled water $1100 \mathrm{ml}$ ) and used for tissue culture. An aliquot of the transport medium was frozen at $-70^{\circ} \mathrm{C}$ and also tested by the amplified ELISA.

\section{VIRUS CULTURE}

Swabs collected in Hanks' transport medium were immediately stored at $4^{\circ} \mathrm{C}$ until inoculated on monolayer cultures of Vero cells. This was usually on the same day, but specimens arriving late in the afternoon were inoculated the next morning. Cells were examined three times a week for cytopathic effect for a maximum of two weeks. Typical cytopathic effect was confirmed by direct immunofluorescence using monoclonal antibodies specific to HSV types 1 and 2, which were labelled with a fluorescein isothiocyanate conjugate (Syva, USA). 


\section{ELISA PROCEDURE}

We used an enzyme amplified immunoassay kit (Wellcome Research Laboratory, Kent, England), which contained test well strips coated with mouse monoclonal antibody to a common antigen type of HSV and control well strips coated with mouse monoclonal antibody of unrelated specificity. The test procedure was as described by Clayton $e t$ al, ${ }^{6}$ using five controls (negative, weakly positive, strongly positive, negative Hanks' transport medium, and negative extraction buffer), except that we used $150 \mu$ l, rather than $50 \mu$, of each sample. The absorbance of each well was read at $492 \mathrm{~nm}$. The cut off values for the transport medium and the extraction buffer were calculated for each run by subtracting the absorbance of the control well from the absorbance of the test well for the transport medium or the extraction buffer and adding $0 \cdot 1$.

\section{NEUTRALISATION TEST}

The presence or absence of HSV antigen in culture negative samples that were positive by ELISA was confirmed by neutralisation. The test sample $(150 \mu \mathrm{l})$ was incubated in assay wells with $25 \mu$ l human serum containing HSV antibody or $25 \mu \mathrm{l}$ seronegative human serum for two hours at room temperature, conjugate was added, and the ELISA performed. An appreciable (more than half) decrease in inhibition of reactivity with specific antibody confirmed the presence of HSV antigen.

\section{Results}

Of the 180 specimens tested, 93 were cell culture positive for HSV. Of the 93 culture positive lesions, 68 were positive by ELISA with both extraction buffer and transport medium, 10 were positive by ELISA with only extraction buffer, and four were positive with only transport medium. The table shows that, compared with culture, ELISA with extraction buffer was $83.9 \%(78 / 93)$ sensitive and $94.3 \%(82 / 87)$ specific, and with transport medium was $77.4 \%$ (72/ 93) sensitive and $96.6 \%(84 / 87)$ specific. Of five samples positive by ELISA with extraction buffer and

Table Culture of herpes simplex virus (HSV) compared with detection of HSV antigen by amplified enzyme linked immunosorbent assay (ELISA) with extracts prepared either direct from extraction buffer or from Hanks' viral transport medium

\begin{tabular}{|c|c|c|c|c|c|}
\hline \multirow[b]{2}{*}{ Culture } & \multirow[b]{2}{*}{ No } & \multicolumn{2}{|c|}{ Extraction buffer } & \multicolumn{2}{|c|}{ Transport medium } \\
\hline & & Positive & Negative & Positive & Negative \\
\hline $\begin{array}{l}\text { Positive } \\
\text { Negative }\end{array}$ & $\begin{array}{l}93 \\
87\end{array}$ & $\begin{array}{r}78 \\
5\end{array}$ & $\begin{array}{l}15 \\
82\end{array}$ & $\begin{array}{r}72 \\
3\end{array}$ & $\begin{array}{l}21 \\
84\end{array}$ \\
\hline Total & 180 & 83 & 97 & 75 & 105 \\
\hline
\end{tabular}

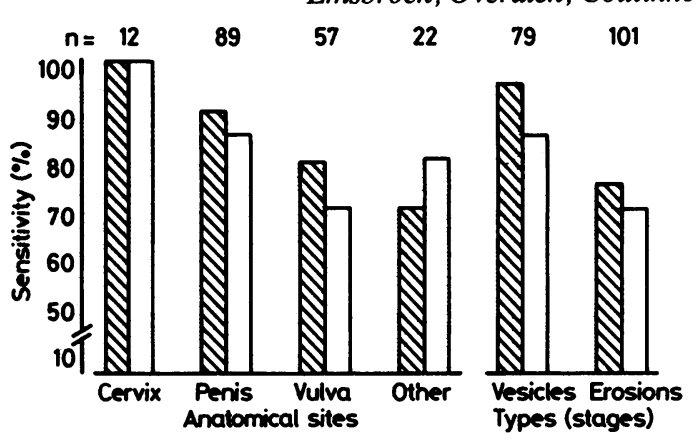

Figure Sensitivity of enzyme linked immunosorbent assay (ELISA) with extracts prepared either direct from extraction buffer (shaded columns) or from Hanks' transport medium (clear columns) in relation to sites and stages of lesions. (Other = from rectum, perianus, and other anatomical sites.)

culture negative, only one was repeatedly positive and neutralised. Of the remaining four samples, two were negative by ELISA when tested again, and two gave borderline results. When excluding these four samples, the specificity of the ELISA with extraction buffer became $98.9 \%(86 / 87)$.

The figure shows the sensitivity of ELISAs performed with either extract related to the stage and site of lesions. Earlier lesions (vesicles) scored higher than later lesions (ulcers) by ELISA with both extraction buffer (sensitivities $93.8 \%(45 / 48) \vee 73.3 \%(33 / 45)$ ) and transport medium (sensitivities 83.3\% (40/48) $v$ $71 \cdot 1 \%(32 / 45))$. Lesions at the cervix and penis scored higher than those at other anatomical sites.

We did not find a significant correlation between the time until cytopathic effect was visible and the stage of the lesion (mean time 3.4 days for vesicles, 3.7 days for ulcers) or between cytopathic effect and the results of the ELISA with extraction buffer (mean time 3.5 days for positive results, $3 \cdot 7$ days for false negative results).

The ELISA with extraction buffer was more sensitive when the directly extracted swab was taken first; $\left(90.7 \% \vee 74.4 \% ; \chi^{2}=3.36 ; 0.05<p<0.1\right)$. The sensitivity of the ELISA with transport medium did not vary with the sequence of sampling $(76.9 \% v$ $77.8 \%$ ). In all groups the specificity varied between 93 and $97.7 \%$ and did not depend on the sequence of sampling.

Of the $93 \mathrm{HSV}$ positive cultures, 11 were HSV1 and 82 HSV2. Of the 11 HSV1 lesions, all were positive by ELISA with extraction buffer and nine by ELISA with transport medium.

\section{Discussion}

We compared a new amplified ELISA with cell culture for detecting HSV. Though the method was rapid and 
easy to perform and in our experience more sensitive than the conventional ELISA, the sensitivity was less than that of our culture technique and depended on the concentration of viral antigens present. When the directly extracted swab was taken first the sensitivity was improved $(90.7 \% v 74.4 \%)$. This may be because some of the antigenic material was removed during the first sampling, leaving too little for the second sample.

Our results are comparable with those of Clayton $e t$ $a l$, who used the same amplified ELISA, ${ }^{6}$ although they did find a somewhat higher sensitivity of the ELISA using extraction buffer $(92 \%)$ than we did $(84 \%)$. This difference may be explained by the type of lesions sampled or by minor differences in culture technique.

Because it would be valuable if ELISA and cell culture could be undertaken from the same specimen sample, we also applied the ELISA to the transport medium. We found no differences in sensitivity between ELISA using transport medium and culture in relation to sequence of sampling, probably because the same sample was used for both procedures. In contrast, two different samples were used for ELISA using extraction buffer. The overall lower sensitivity of the ELISA using transport medium (77.4\%) may be explained by the greater dilution of virus antigen, as we used $2 \mathrm{ml}$ transport medium for culture and $1 \mathrm{ml}$ extraction fluid for the ELISA. Clayton et al also found a lower sensitivity of the ELISA with transport medium $(78 \%)$ than with extraction buffer $(92 \%){ }^{6}$ Morgan et al found a decrease of $15 \%$ in antigen detection with another ELISA by using $3 \mathrm{ml}$ transport medium instead of $2 \cdot 2 \mathrm{ml}^{3}$

The importance of the antigen load for the ELISA, as for culture, is also reflected in the stage of the lesion. Greater concentrations of virus are found in vesicles than in ulcers, which is reflected in the results of the cultures: 48/79 vesicles positive and 45/101 ulcers positive. The ELISA with extraction buffer, however, gave positive results in 45/79 of vesicles and 33/101 of ulcers, which means a sensitivity (compared with culture) of respectively $93.8 \%$ and $73.3 \%$ (Fisher's exact test, two sided; $p<0.02$ ). The ELISA apparently depends more than culture on a high virus concentration. This may also explain the greater sensitivity of the ELISA with extraction buffer (compared with culture) for HSV1 (11/11 positive, sensitivity $100 \%)$ than for HSV2 (67/82 positive, sensitivity $81 \%)$. Of the 11 HSV1 infections, only one was recurrent, whereas of the 82 HSV2 infections, 25 were recurrent. There is probably less virus (and antigen) during a recurrence.

The predictive value, compared with culture, of a positive result by ELISA with extraction buffer was $94 \%$ and of a negative result $85 \%$. For patient groups with a high prevalence of HSV infection this test is therefore an alternative to cell culture. In early lesions, however, when sensitivity of the ELISA with extraction buffer is high $(93.8 \%)$ the diagnosis of genital herpes depends mostly on clinical appearance, and laboratory confirmation is not absolutely necessary. In later lesions (ulcers), which are often difficult to differentiate on clinical grounds from genital ulcers with other causes, the sensitivity of the ELISA with extraction buffer is still rather low $(73 \cdot 3 \%)$ and culture remains the first choice. In our hands the specifity of the ELISA with extraction buffer, if performed once, was about $95 \%$, and we therefore cannot recommend this test for screening populations with a low prevalence of HSV (for example symptomless pregnant women just before delivery).

This ELISA, like others, does not differentiate between HSV1 and HSV2. This is important for counselling patients with genital herpes, as recurrences of HSV2 are more frequent.

In conclusion, this amplified ELISA gives better results than the conventional ELISA with clinical specimens and may be used when culture facilities are not easily available. It has the advantage of speed and simplicity, but cannot replace culture for screening of low prevalence groups.

We thank Wellcome Research Laboratories for providing the test material, Dr S M Chantler (Wellcome), for her valuable comments, and Mrs A Nat for preparing the manuscript.

\section{References}

1 Grillner L, Landquist L. Enzyme-linked immunosorbent assay for detection and typing of herpes simplex virus. Eur $J$ Clin Microbiol 1983;2:39-42.

2 Miranda QR, Bailey GD, Fraser AS, Tenoso HJ. Solid-phase enzyme immunoassay for herpes simplex virus. $J$ Infect Dis 1977;136suppl:S304-10.

3 Morgan MA, Smith TF. Evaluation of an enzyme-linked immunosorbent assay for the detection of herpes simplex virus antigen. J Clin Microbiol 1984;19:730-2.

4 Lawrence TG, Budzko DB, Wilcke BW. Detection of herpes simplex virus in clinical specimens by an enzyme-linked immunosorbent assay. Am J Clin Pathol 1984;81:339-41.

5 Alexander I, Ashley CR, Smith KJ, Harbour J, Roome A, Darville JM. Comparison of ELISA with virus isolation for the diagnosis of genital herpes. J Clin Pathol 1985;38:554-7.

6 Clayton AL, Roberts C, Godley M, Best JM, Chantler SM. Herpes simplex virus detection by ELISA: effect of enzyme amplification, nature of lesion sampled and specimen treatment. $J$ Med Virol 1986;20:89-99. 